\title{
Spirulina-based Dietary Supplement
}

National Cancer Institute

\section{Source}

National Cancer Institute. Spirulina-based Dietary Supplement. NCI Thesaurus. Code C158092.

A nutritional supplement composed of the blue-green microalgae spirulina. Spirulina is high in protein and contains significant amounts of calcium, niacin, potassium, magnesium, B vitamins, vitamin E, iodine, iron, beta-carotene, phycocyanin and chlorophyll. The spirulina dietary supplement may affect the cardiovascular, digestive and immune systems and may improve diabetes and high cholesterol. In addition, spirulina contains antioxidants and may protect against cellular DNA damage by reactive oxygen species (ROS). As spirulina has a high concentration of iodine and contains the amino acid tyrosine, it may improve thyroid function, and ameliorate the size of benign thyroid nodules. 